\title{
Análise do uso da informação para tomada de decisão gerencial em nível de gestão de pessoas
}

Discente: Thais Carrier Mendonça

Orientador: Dr. Gregório Jean Varvakis Rados - PGCIN/UFSC

Banca: Dra. Gleisy Regina Bóries Fachin - CIN/UFSC

Dr. Márcio Matias - CIN/UFSC

Dr. Vinícius Medina Kern - PGCIN/UFSC

Dra. Magda Teixeira Chagas - PGCIN/UFSC

Dr. Paulo Maurício Selig - EGC/UFSC

\section{RESUMO}

O setor bancário trabalha acentuadamente com a informação e tem se destacado no mercado pelo forte uso e investimento em tecnologias da informação. Assim, entender como os fluxos de informação ocorrem neste setor tornou-se instigante e enriquecedor para o campo da Ciência da Informação. Buscou-se analisar o uso da informação para tomada de decisão, em gestão de pessoas, de gestores de agências bancárias. Delimitase como objetivos específicos: (i) identificar os canais e fontes de informação utilizadas; (ii) identificar as principais barreiras enfrentadas na busca e acesso às informações; (iii) descrever os usos das informações do sistema de informação gerencial desenvolvido pela empresa; (iv) verificar a qualidade percebida pelos gestores em relação ao sistema de informação gerencial. A pesquisa é do tipo estudo de caso e foi realizada com gestores de agências bancárias de Santa Catarina. Obteve-se uma amostra de 273 gestores, correspondentes a quantidade de gestores que responderam o questionário on-line. A análise do uso da informação foi verificada sob três categorias: (i) canais e fontes de informação; (ii) Barreiras de acesso à informação; (iii) Sistemas de informação gerencial. Os resultados revelam que os canais e fontes internas formais são aqueles preferidos pelos gestores, tais quais aos normativos internos (95\%, 258 apontamentos), Intranet (91\%, 249 apontamentos) e Informativos internos (73\%, 199 apontamentos). As barreiras de acesso a informação mais enfrentadas pelos gestores quando na busca por informações foram a sobrecarga informacional (67\%, 184 apontamentos) seguido da falta de tempo (62\%, 170 apontamentos). Aspectos como linguagem, terminologia e material desatualizado foram pouco percebidos como barreiras de acesso a informação. A categoria sistema de informação gerencial observou a qualidade e finalidades de uso do sistema de informação gerencial desenvolvido pela empresa. A análise dos dados mostrou que os gestores precisam de muita informação para a tomada de decisão e, no caso da instituição em estudos, essas informações são encontradas no âmbito interno da instituição bancária. Considera-se que aspectos da gestão da informação contribuem para a melhoria da gestão empresarial. Por fim, conclui-se que o sistema de informação gerencial é uma ferramenta inovadora passível de ser utilizada em outros contextos organizacionais. 0 uso da informação para tomada de decisão em gestão de pessoas na instituição bancária trouxe subsídios relevantes para entender como e quando as informações se tornam úteis aos usuários de informação.

Palavras-chave: Uso da informação. Instituição Bancária. Tomada de decisão gerencial. Gestão de Pessoas. 